\title{
Switchable Fluorescent Organogels and Mesomorphic Superstructure Based on Naphthalene Derivatives
}

Hong Yang, Tao Yi ${ }^{*}$, Zhiguo Zhou, Yifeng Zhou, Juncheng Wu, Miao Xu, Fuyou Li ${ }^{*}$, Chunhui Huang Department of Chemistry \& Laboratory of Advanced Materials, Fudan University, Shanghai 200433, People's Republic of China

Email: yitao@fudan.edu.cn, fyli@fudan.edu.cn

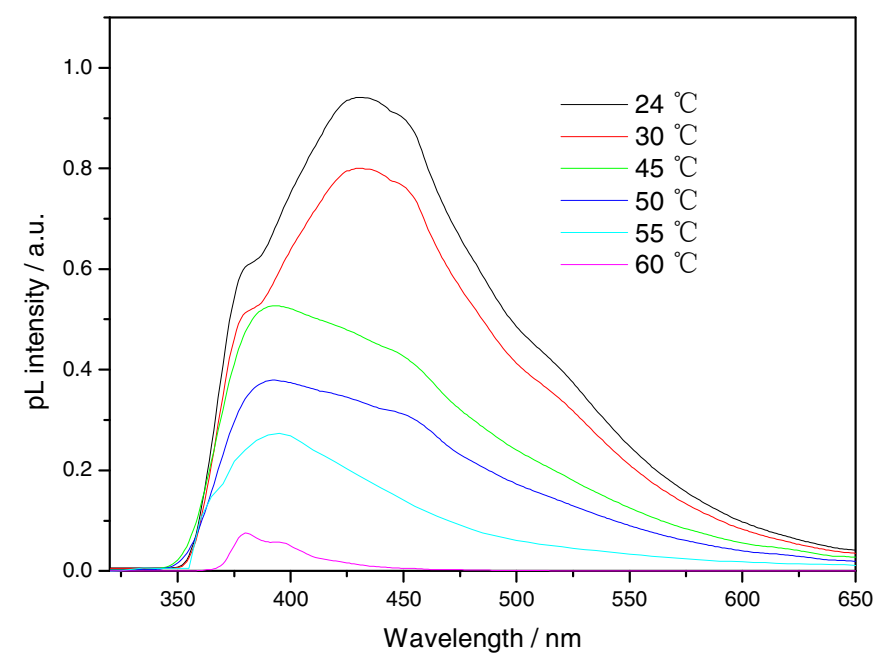

Figure S1. Variable-temperature fluorescent spectra of 1a with a high concentration in 1, 4 dioxane $(22 \mathrm{mg} / \mathrm{mL})(\lambda$ ex: $310 \mathrm{~nm})$

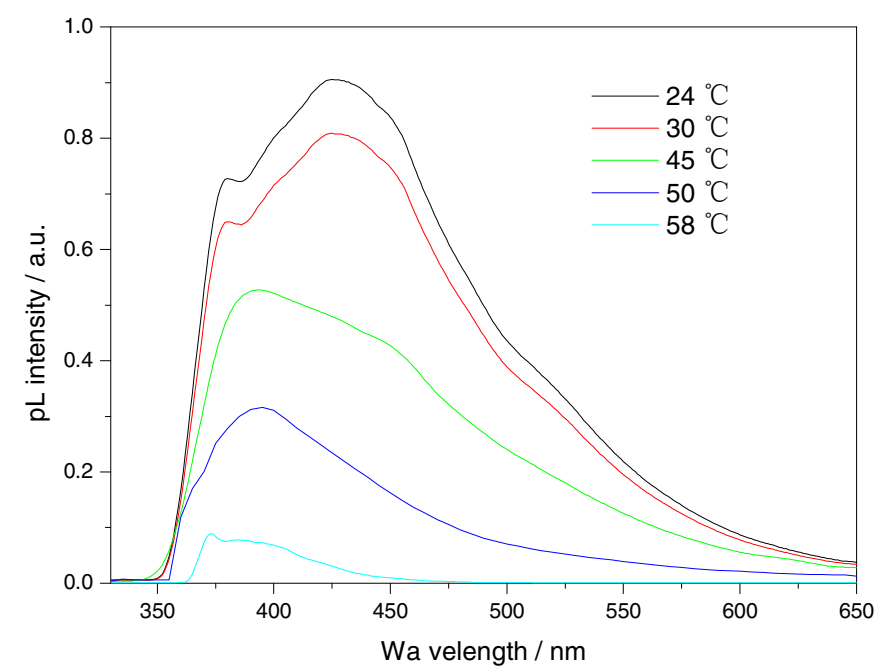

Figure S2. Variable-temperature fluorescent spectra of $\mathbf{1 c}$ with a high concentration in 1, 4- dioxane $(22 \mathrm{mg} / \mathrm{mL})(\lambda \mathrm{ex}: 310 \mathrm{~nm})$ 


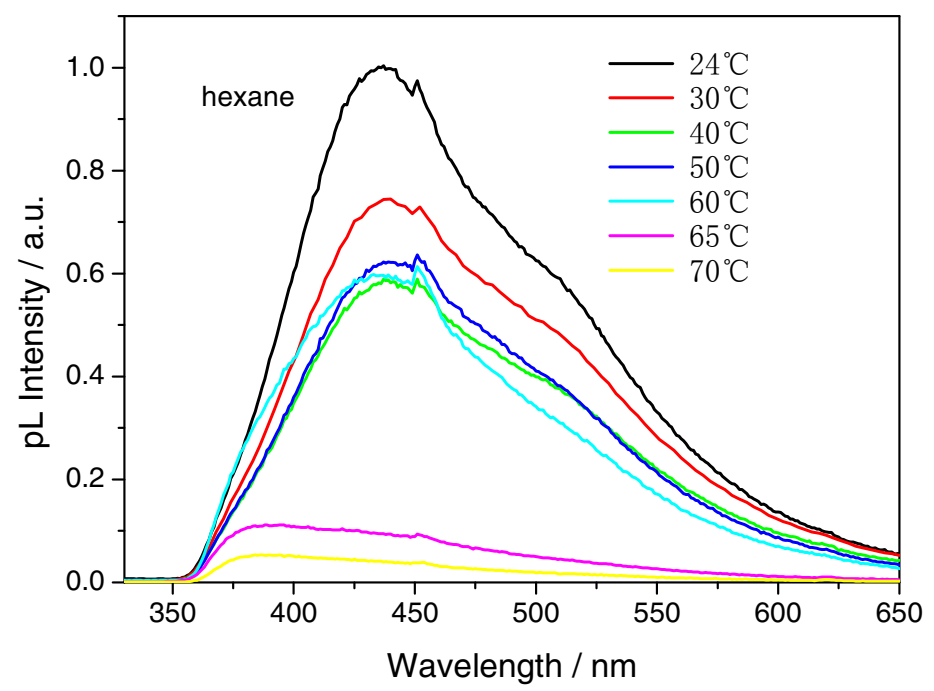

Figure S3. Variable-temperature fluorescence spectra of gel1b $(12 \mathrm{mg} / \mathrm{mL})$ in hexane $\left(\lambda_{\text {ex }}: 310 \mathrm{~nm}\right)$.

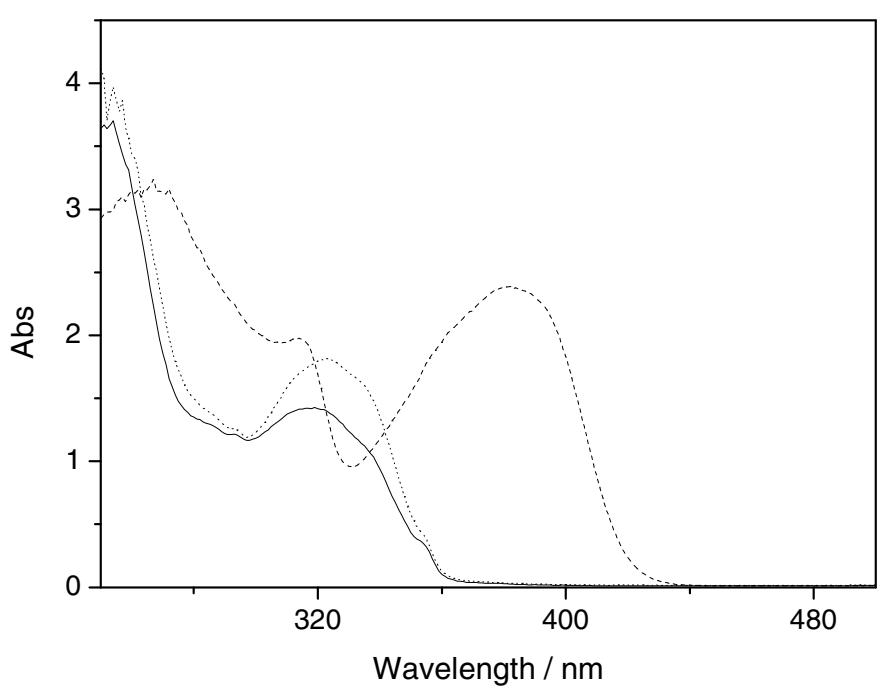

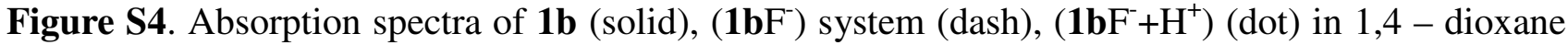
solution at room temperature $\left(1.0 \times 10^{-4} \mathrm{~mol} / \mathrm{L}\right)$. 


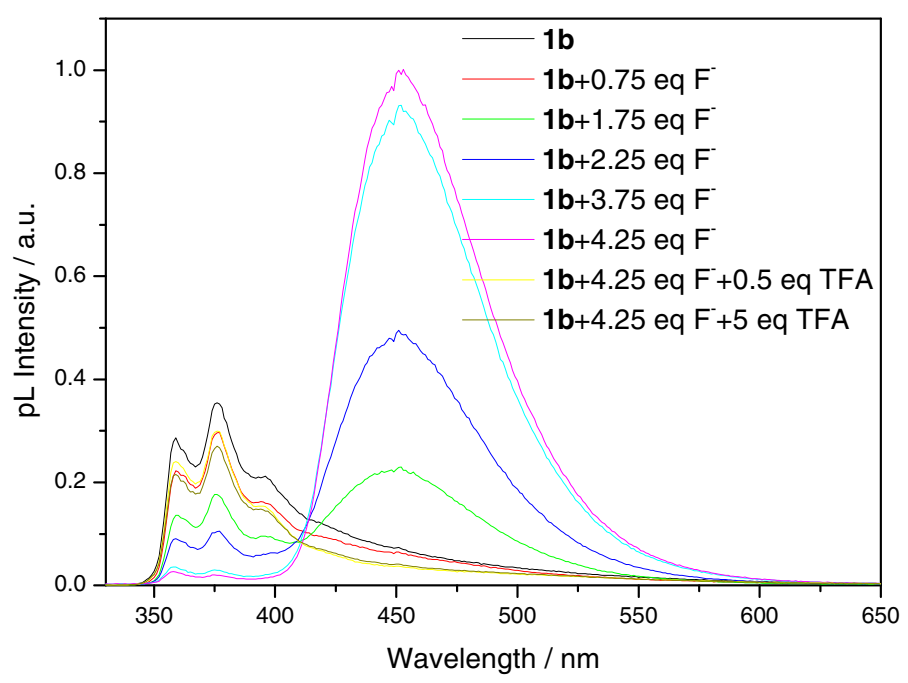

Figure S5. Fluorescent spectra of $\mathbf{1 b}$ in the presence of fluoride anions and TFA at room temperature in 1,4 - dioxane solution $\left(1.0 \times 10^{-4} \mathrm{~mol} / \mathrm{L}, \lambda_{\mathrm{ex}}: 310 \mathrm{~nm}\right)$

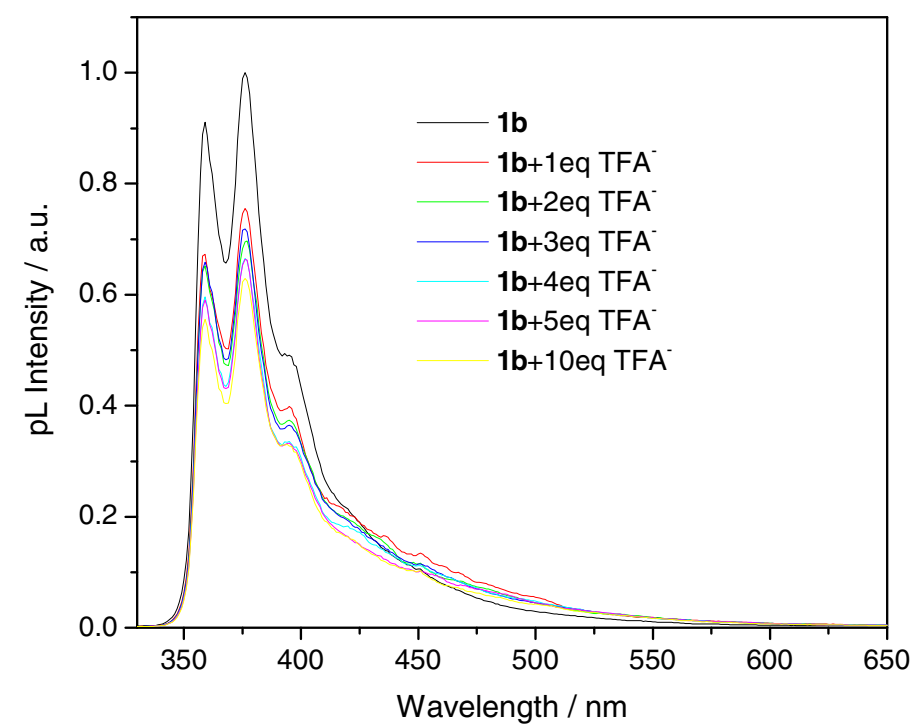

Figure S6. Fluorescent spectra of $\mathbf{1 b}\left(1.0 \times 10^{-4} \mathrm{~mol} / \mathrm{L}\right)$ in the presence of trifluoroacetate $\left(\mathrm{TFA}^{-}\right)$at room temperature in $1,4-$ dioxane solution $\left(\lambda_{\mathrm{ex}}: 310 \mathrm{~nm}\right)$ 


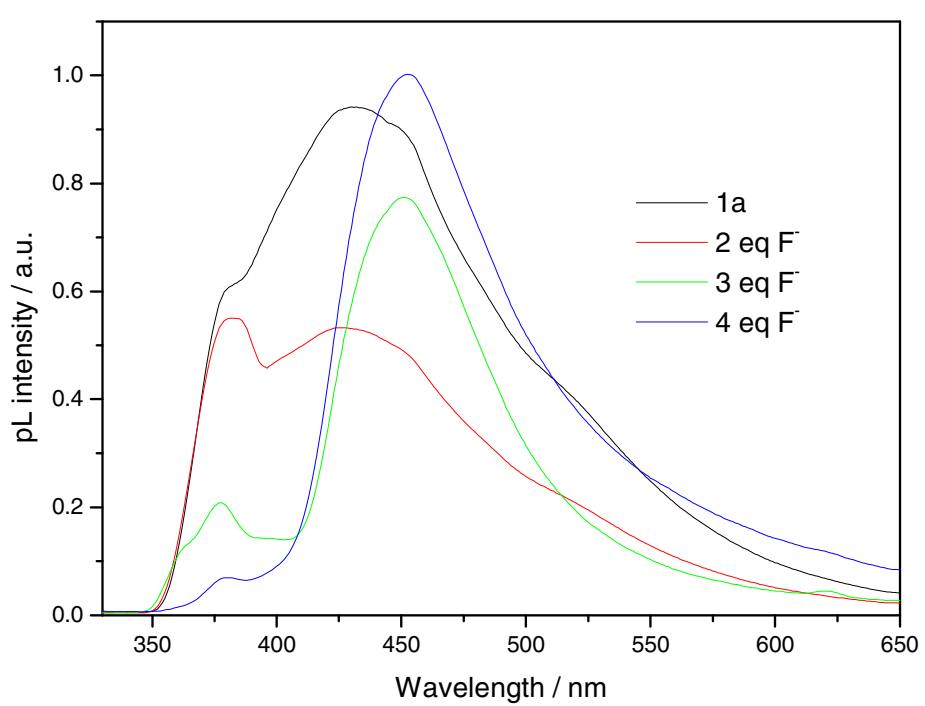

Figure S7. Fluorescence spectra of $1 \mathbf{a}(22 \mathrm{mg} / \mathrm{mL})$ in the presence of different contents of fluoride anions at room temperature in $1,4-$ dioxane gel $\left(\lambda_{\text {ex }}: 310 \mathrm{~nm}\right)$

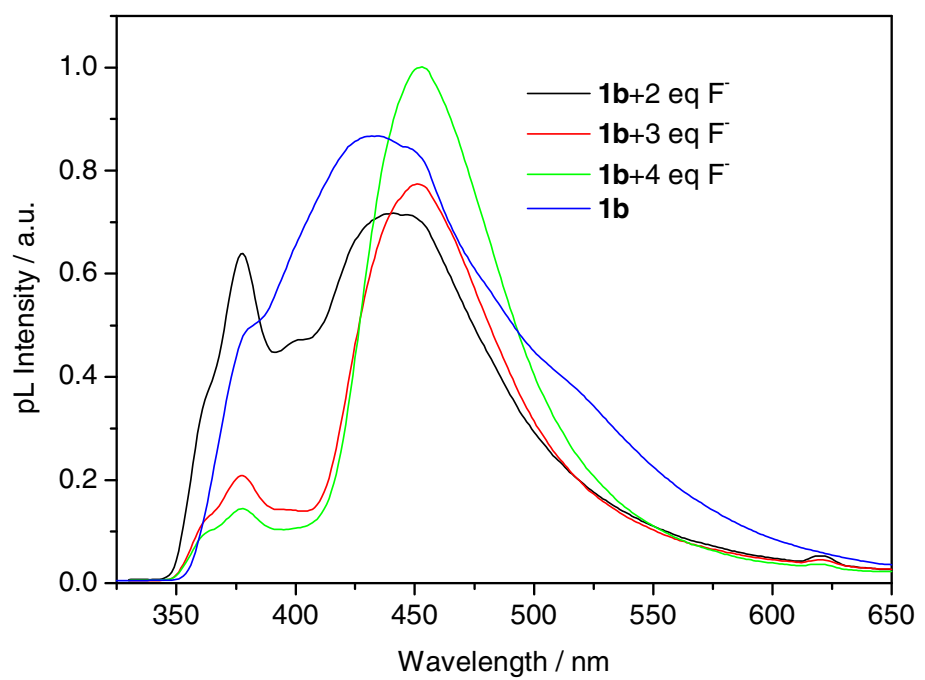

Figure S8. Fluorescence spectra of $\mathbf{1 b}(22 \mathrm{mg} / \mathrm{mL})$ in the presence of different contents of fluoride anions at room temperature in 1,4 - dioxane gel $\left(\lambda_{\mathrm{ex}}: 310 \mathrm{~nm}\right)$

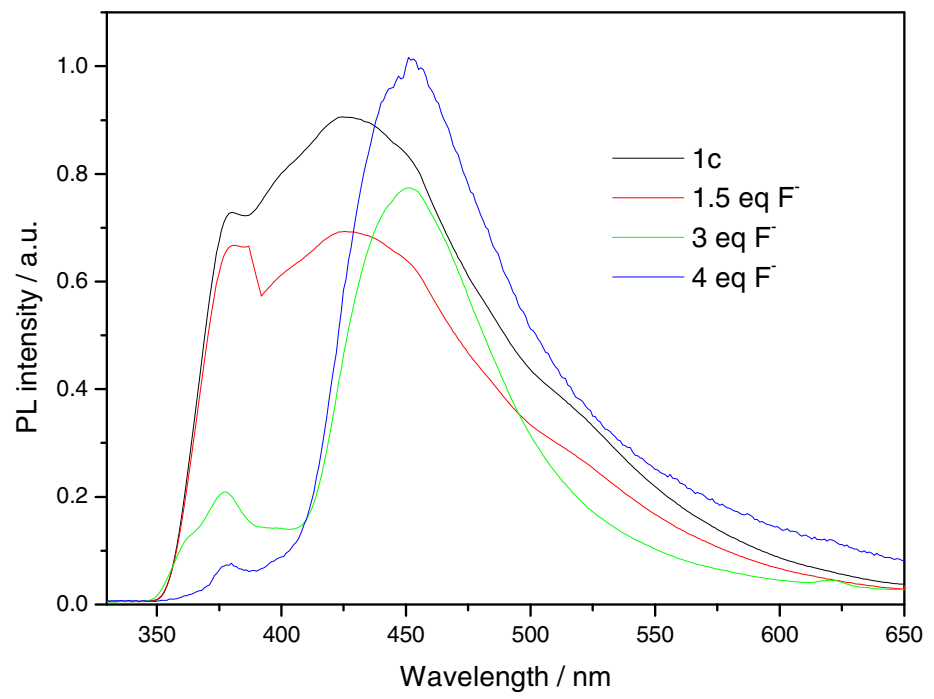


Figure S9. Fluorescence spectra of $1 \mathbf{c}(22 \mathrm{mg} / \mathrm{mL})$ in the presence of different contents of fluoride anions at room temperature in $1,4-$ dioxane gel $\left(\lambda_{\text {ex }}: 310 \mathrm{~nm}\right)$

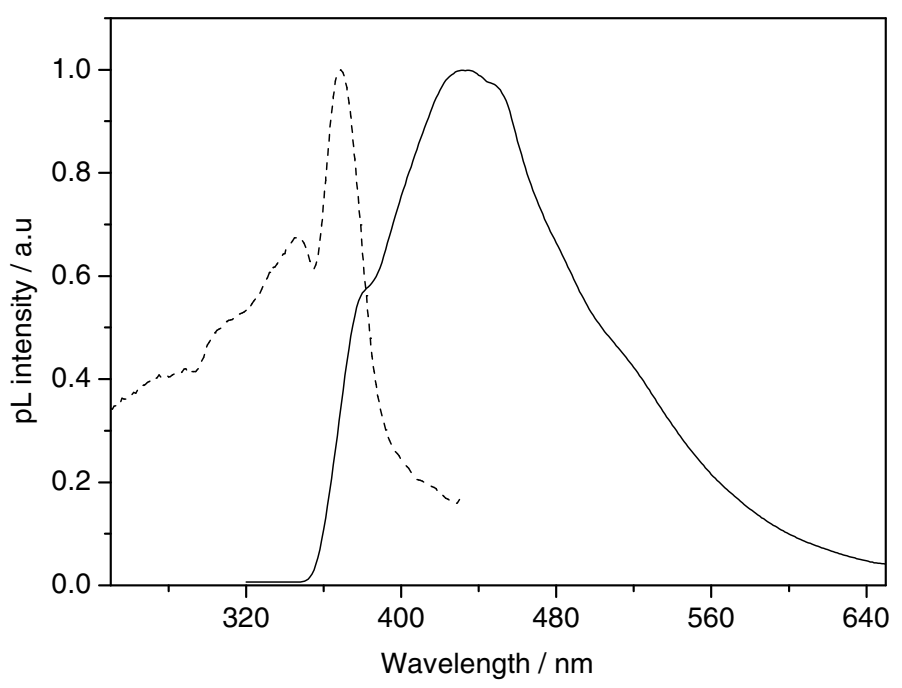

Figure S10. Emission (Ex: $310 \mathrm{~nm}$, solid) and excitation (Em: $440 \mathrm{~nm}$, dash) spectra of 1b gels in 1,4 - dioxane at room temperature $(22 \mathrm{mg} / \mathrm{mL})$.

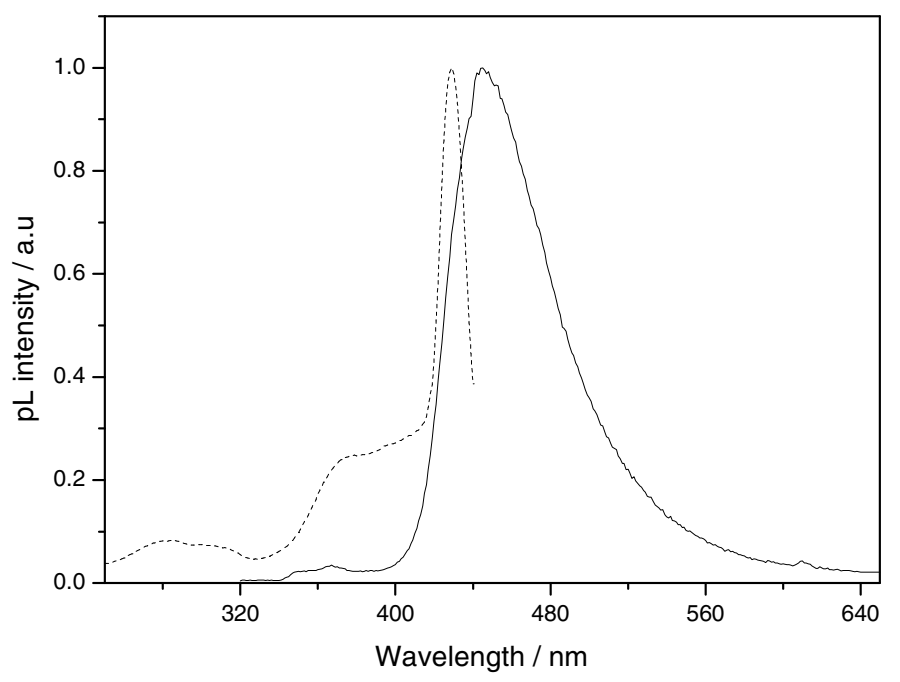

Figure S11. Emission (Ex: $310 \mathrm{~nm}$, solid) and excitation (Em: $450 \mathrm{~nm}$, dash) spectra of 1bF${ }^{-}$in 1,4 dioxane at room temperature $(22 \mathrm{mg} / \mathrm{mL})$. 


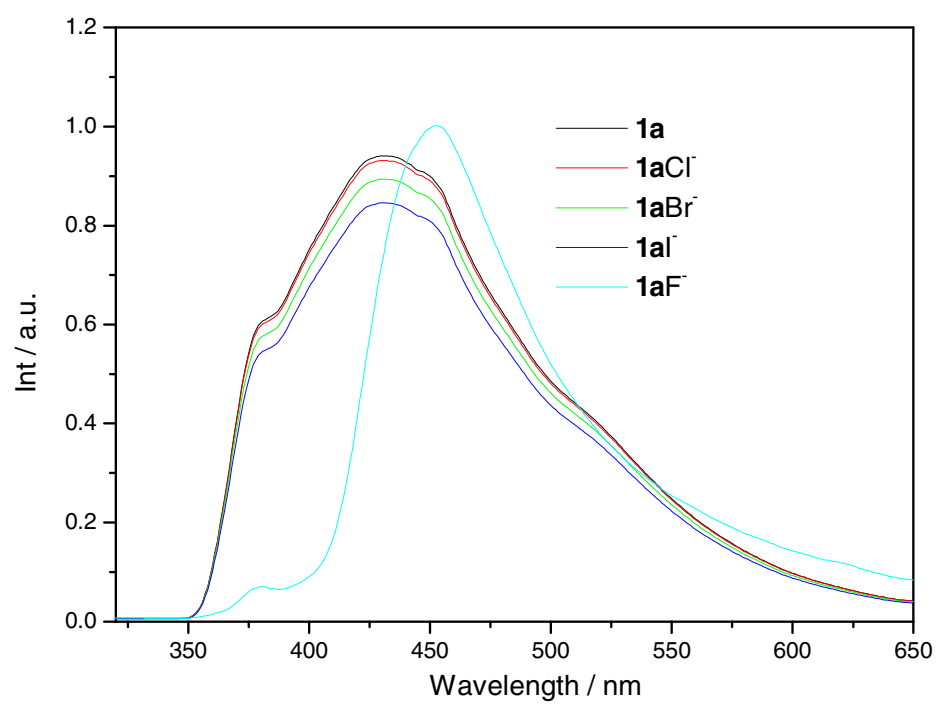

Figure S12. Fluorescence spectra of $1 \mathbf{a}(22 \mathrm{mg} / \mathrm{mL})$ in the presence of different contents of halide anions at room temperature in 1,4-dioxane gel $\left(\lambda_{\mathrm{ex}}: 310 \mathrm{~nm}\right)$

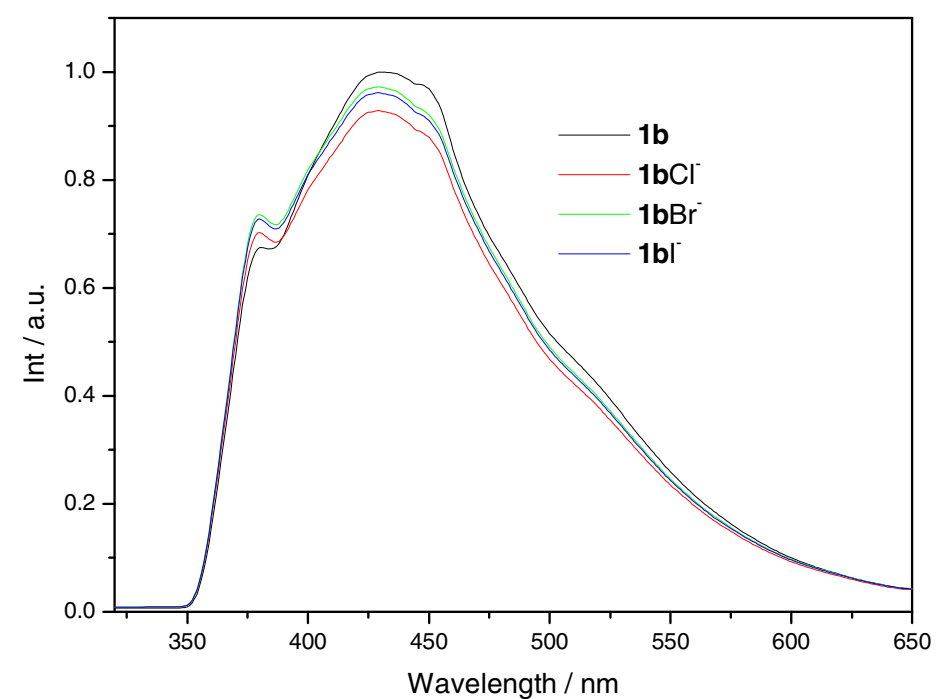

Figure S13. Fluorescence spectra of $\mathbf{1 b}(22 \mathrm{mg} / \mathrm{mL})$ in the presence of different contents of halide anions at room temperature in $1,4-$ dioxane gel $\left(\lambda_{\text {ex }}: 310 \mathrm{~nm}\right)$ 


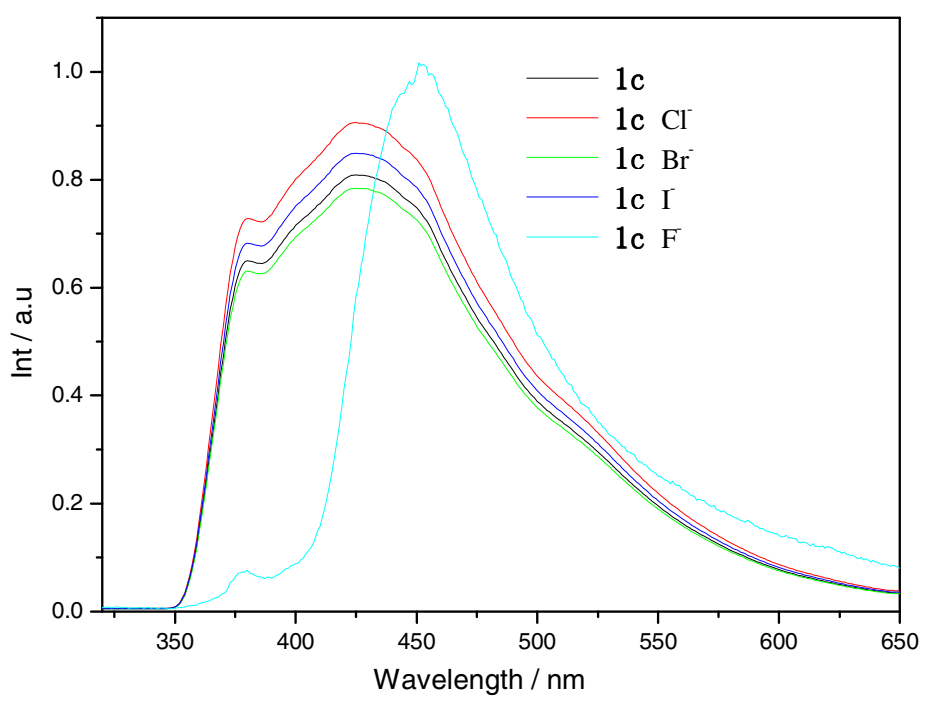

Figure S14. Fluorescence spectra of $1 \mathbf{c}(22 \mathrm{mg} / \mathrm{mL})$ in the presence of different contents of halide anions at room temperature in 1,4-dioxane gel $\left(\lambda_{\mathrm{ex}}: 310 \mathrm{~nm}\right)$

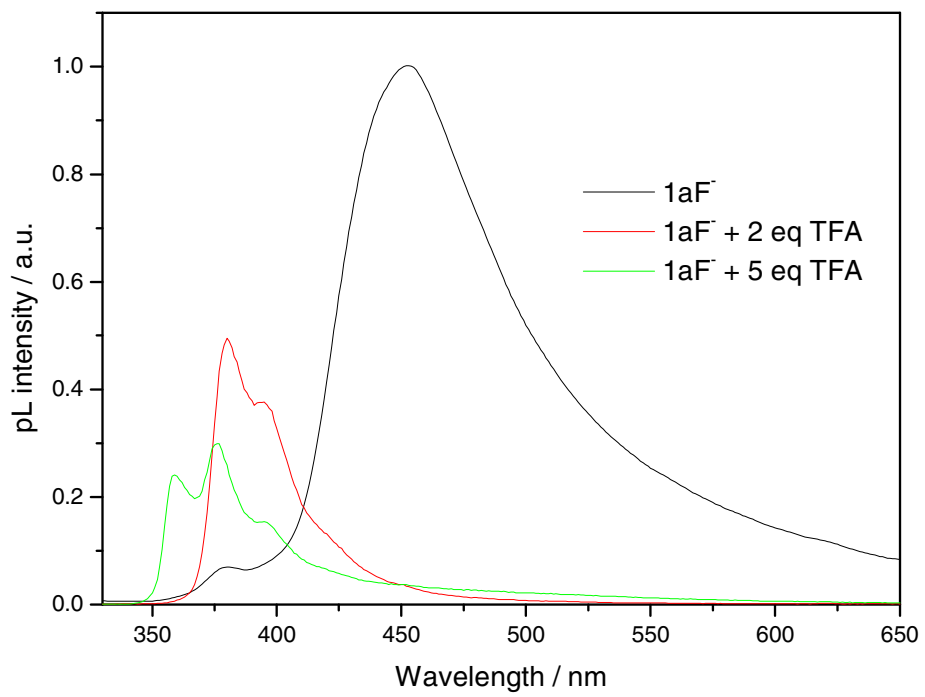

Figure S15. Fluorescence spectra of $1 \mathbf{a F}^{-}$sol $(22 \mathrm{mg} / \mathrm{ml})$ in the presence of different contents of TFA at room temperature in $1,4-$ dioxane $\left(\lambda_{\text {ex }}: 310 \mathrm{~nm}\right)$ 


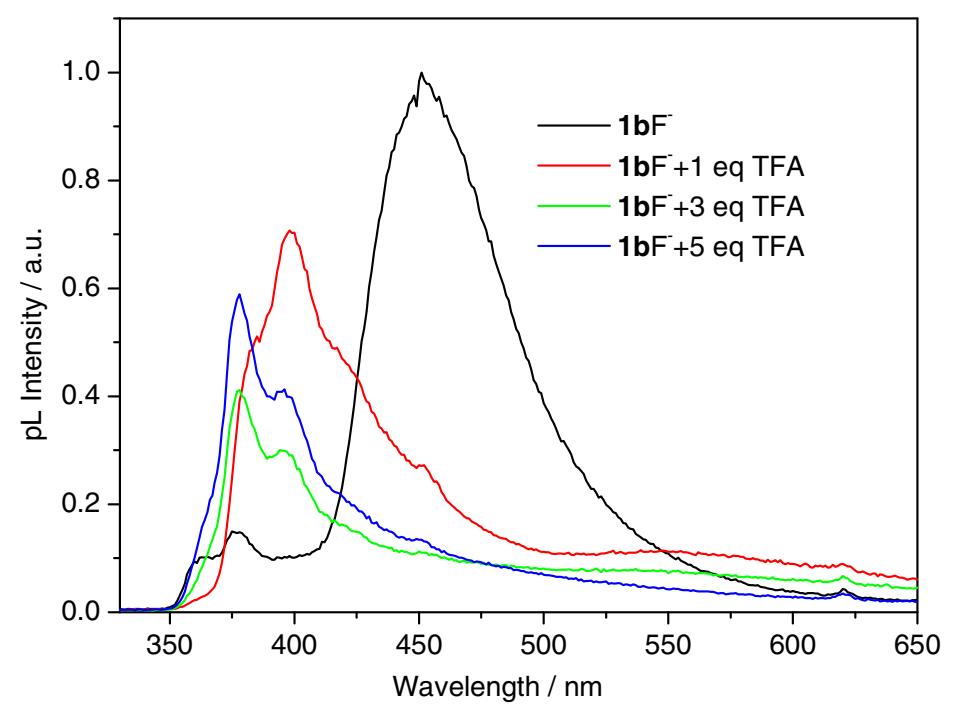

Figure S16. Fluorescence spectra of $\mathbf{1 b F}^{-}$sol $(22 \mathrm{mg} / \mathrm{ml})$ in the presence of different contents of TFA at room temperature in $1,4-$ dioxane $\left(\lambda_{\text {ex }}: 310 \mathrm{~nm}\right)$

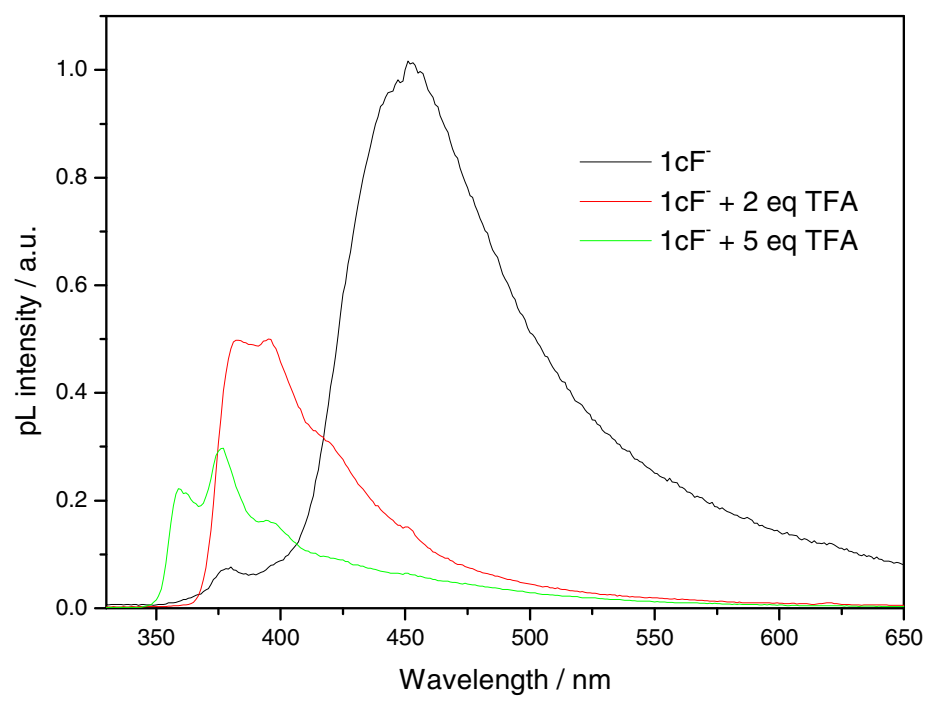

Figure S17. Fluorescence spectra of $\mathbf{1} \mathrm{cF}^{-}$sol $(22 \mathrm{mg} / \mathrm{ml})$ in the presence of different contents of TFA at room temperature in $1,4-$ dioxane $\left(\lambda_{\text {ex }}: 310 \mathrm{~nm}\right)$ 


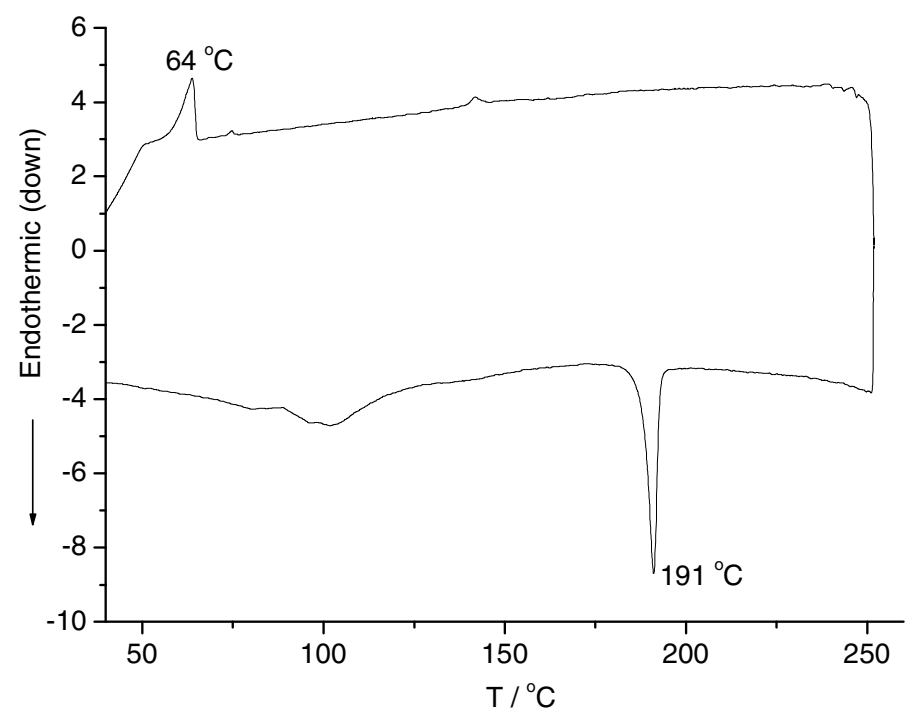

Figure S18. DSC curves of 1a on the first heating and cooling cycles

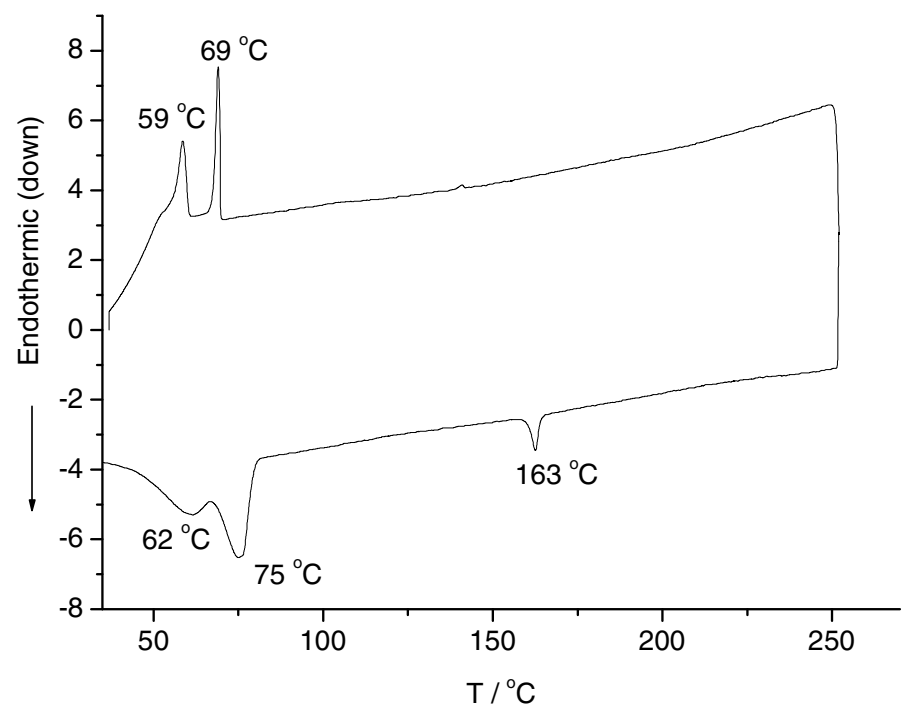

Figure S19. DSC curves of 1c on the first heating and cooling cycles

The cell parameters of $\mathbf{1 b}$ were calculated according the flowing models.

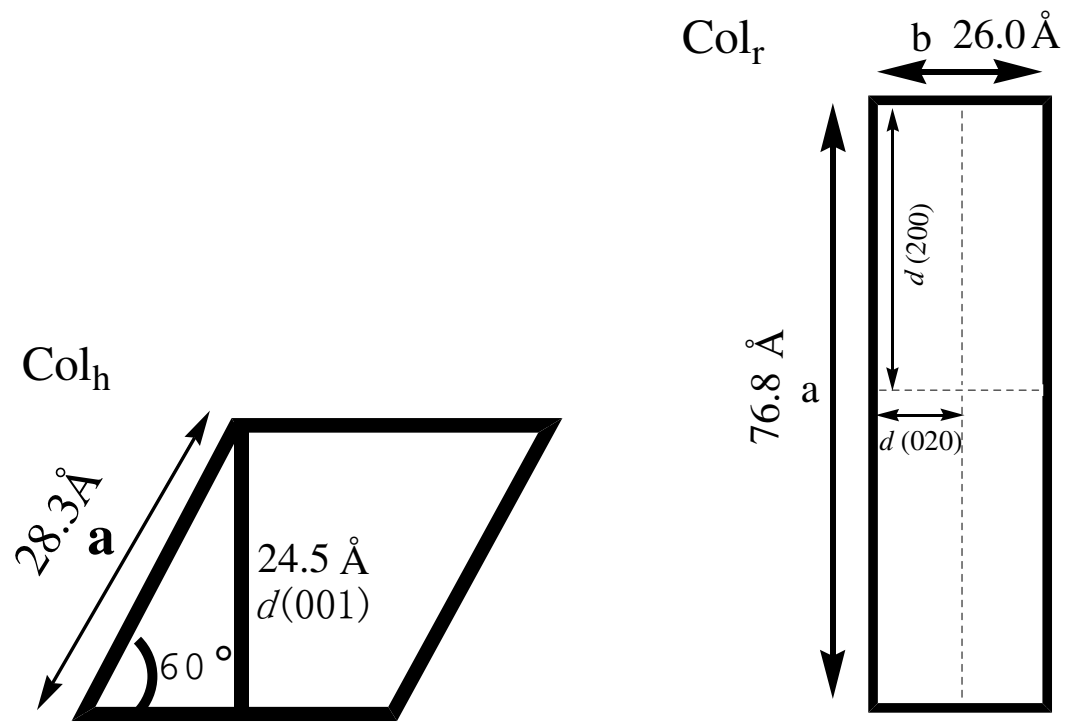

